\title{
Value Analysis: Capturing Total Cost of Ownership reduction opportunities in E\&P projects
}

\author{
E. van der Schans ${ }^{1,2}$, J.W.N. van Lijssel ${ }^{2}$ and P. van Steenderen ${ }^{2}$ \\ 1 Corresponding author; e-mail: e.van.der.schans@e-c.storkgroup.com \\ 2 Stork Engineers and Contractors B.V., Radarweg 60, NL 1043 NT Amsterdam
}

Manuscript received: 30 May 1999; accepted in revised form 18 May 2000

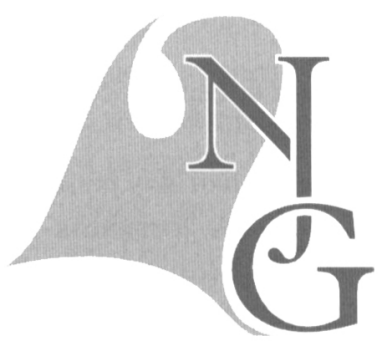

\begin{abstract}
Value Analysis is a powerful tool to increase the value of a capital investment project and to capture cost saving opportunities. It is a method conceived during World War II and frequently used on infrastructure projects, especially in the USA.

The Value Analysis process typically consists of a well prepared 3 to 5 day workshop with focus on generating ideas to improve the current engineering concept. Emphasis is on screening all proposals in order to identify the most promising ideas. The workshop results in a number of proposals to modify the existing engineering concept.

Stork Engineers \& Contractors have used the Value Analysis method on several projects as well as in proposals for Engineering, Procurement and Construction (EPC) projects in the Exploration and Production (EP) industry.

Typical results of Value Analysis led to a decrease of Total Cost of Ownership by some 10 to $30 \%$. A well facilitated Value Analysis workshop also leads to mutual trust and understanding between the parties involved.

A key element in a Value Analysis is (re)definition of the proposed functionality of a project. This is done through challenging the existing technical concept by increasing this functionality or by meeting this functionality at a lower cost.
\end{abstract}

Keywords: value analysis, value management, total cost of ownership, function analysis system technique, cost reduction

\section{Introduction}

Forced by low oil prices and a highly competitive market, Exploration and Production (EP) operating companies as well as contractors seek to minimize costs. Two trends are clearly visible in this market:

More and more the traditional focus on total installed cost is moving towards a Total Cost of Ownership (TCoO) approach. In TCoO capital expenditure, operational expenditure as well as maintenance expenditure are taken into account for the full lifecycle of an installation. In addition Exploration and Production (EP) operating companies increasingly award contracts on a lumpsum turnkey (LSTK) basis instead of the classic format of reimbursable contracts. In the LSTK approach the contractor is given more freedom to implement a cost-effective design within boundary conditions of quality, planning, reliability, safety, etc. as specified by the operating company.

As the largest Dutch engineering contractor, Stork Engineers \& Contractors is facing a more and more competitive market, a market where clients demand the highest value for their money. An innovative method in the Exploration and Production (EP) industry to enhance value is Value Analysis.

Value Analysis, also known as Value Engineering or Value Management, is a method to reduce cost or to increase functionality. The roots of the method originate from World War II military projects where the 
primary focus was on reducing costs, while maintaining the essential functionality.

The technique of Value Analysis has proven to be successful in other industrial areas and results in the Exploration and Production (EP) industry indicate, that it is a valuable addition to the tools available to reduce Total Cost of Ownership (TCoO).

\section{The concept of value}

The value of a product can be judged differently by different clients. This is true in the consumer market, where for example the taste and preferences of each individual car buyer will make him/her choose from a wide range of brands, models and colors. Consumers base their buying decision on the optimum value for their money based on their individual interpretation of value.

In general this also holds true for most industrial customers. For industrial customers, such as Exploration and Production (EP) operating companies, value can be expressed as the functionality per cost unit:

$$
\text { value }=\frac{\text { functionality }}{\text { costs }}
$$

Fig. 1. The definition of value.

Value Analysis aims at increasing the value by either reducing the cost or increasing the functionality. It should be noted, that both functionality and cost should be interpreted in the broadest sense. For example functionality can have dimensions such as:

capacity,

product quality,

production flexibility,

fewer months to production start-up,

etc.

\section{Organizing a value analysis}

\section{For which type of project is value analysis used?}

The Value Analysis method is typically used on projects with high investment costs such as infrastructure projects. The US federal government is aware of the cost reduction opportunities created by Value Analysis. Therefore, it is mandatory in the USA to perform a Value Analysis for all construction projects funded by the Department of Interior with an awarded budget of more than USD 500,000.
Despite its widespread application in the US federal government, the method of Value Analysis is not widely known in the Exploration and Production (EP) industry. However, typical Engineering, Procurement and Construction (EPC) projects within the Exploration and Production (EP) industry far exceed this USD 500,000 threshold value. Therefore, Stork Engineers \& Contractors prefers to apply Value Analysis to all new Engineering, Procurement and Construction (EPC) projects and even to engineering proposals, since Value Analysis is a structured approach to capture cost saving opportunities.

\section{Contributors to a value analysis}

Key contributors to the Value Analysis are all stakeholders of the project, as a thorough understanding of possible functionalities and cost-saving opportunities are not necessarily vested in a single party or person. Therefore, the client and partners (main equipment and/or service suppliers) are invited tot participate in the Value Analysis workshop. The contribution of our stakeholders has proven to be a key success factor.

\section{Scheduling a value analysis workshop}

Before starting the Value Analysis, the engineering design should have some level of completeness to provide sufficient information and a realistic cost estimate. On the other hand the Value Analysis can result in major changes in the design. Typically the optimum timing of a Value Analysis is sometime between completion of the basic engineering and prior to the detailed engineering.

For a basic engineering contractor the Value Analysis will be worthwhile, when the basic engineering design is close to completion. However, for an Engineering, Procurement and Construction (EPC) contractor the Value Analysis workshop can best be scheduled either during the proposal phase or shortly after the project award.

\section{Organizing the workshop}

Conducting a Value Analysis takes eight steps. These will take a team through a clear definition of goals, a diverging brainstorm and a converging screening to retain the workable cost-saving ideas.

Before starting a Value Analysis workshop the objectives, expectations and boundary conditions should be jointly defined in an approach plan by the project management and the other stakeholders.

A good understanding of the existing technical 


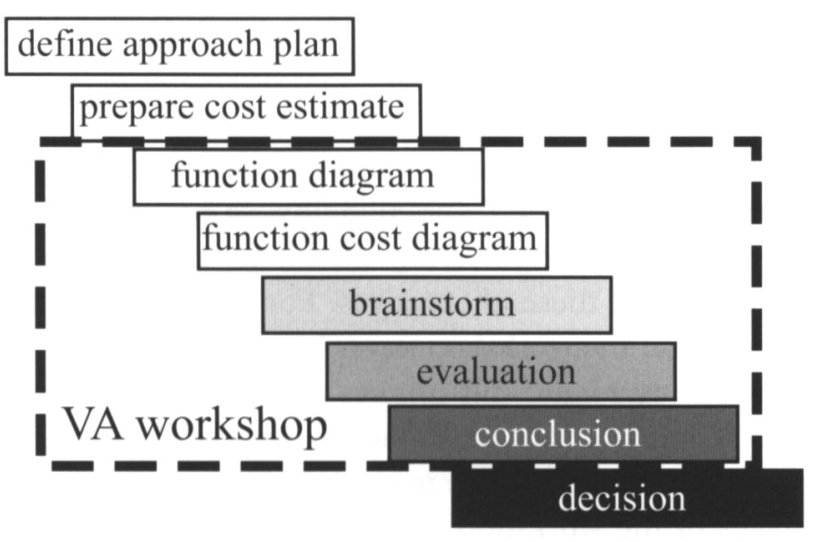

Fig. 2. The Value Analysis process.

concept as well as a realistic cost estimate is required before starting the workshop. During the workshop the persons, that are fully familiar with the existing technical concept and/or the cost estimate should be available for consultation by the Value Analysis team.

The team composition depends on the chosen approach and expectations. However, the team members should be open-minded, creative and willing to deviate from the existing technical concept.

A typical Value Analysis workshop will convene for 3 to 5 days. It will go through a process of identifying the essential functions via brainstorming on technical alternatives or improvements. This will lead to a detailed evaluation of those ideas to prepare series of proposals to increase the project's value. Most time is normally spent evaluating those new ideas. This takes usually more than $50 \%$ of the workshop's time.

\section{Reporting of a value analysis}

The conclusion of the Value Analysis workshop usually consists of a number of proposals to modify the original approach. Each of these proposals should include a study plan to check, whether the expected benefits are realistically achievable.

The workshop's conclusions are presented to the (project) management. It remains the (project) management's responsibility to decide, which proposals should be implemented and to what extent they should be implemented.

\section{Costs of a value analysis workshop}

Before starting a Value Analysis workshop, (project) management should be aware that the workshop and the consequences of the workshop also require an investment in time and money.
During the workshop key staff members will be unavailable for other tasks for 3 to 5 days. Moreover, following the workshop there will be numerous change proposals to be implemented in the design. This will lead to additional engineering costs and possibly also to a delay in completing the engineering phase.

\section{Key elements in a value analysis}

The success of Value Analysis relies on systematically addressing four key elements of the design process:

1. Take manageable risks;

2. Think in functionalities;

3. High focus on key design features;

4. Extensive screening of ideas.

\section{Take manageable risks}

Rather than designing all risks out of an installation, it has proven to be feasible to take manageable risks. This implies for example, that it is accepted, that an installation may not deliver $100 \%$ quality and capacity in a worst-case scenario of combined unfavorable factors.

Client involvement in the workshop enhances the willingness to take manageable risks. It is the client, who is fully aware of the requirements and the acceptability of certain risks. Faced with the sometimes enormous costs of meeting all possible requirements on quality or availability, the client is able to review and prioritize those requirements.

To take manageable risks, an open mind and a willingness to modify the current technical concept is required. This willingness to take manageable risks differs between cultures (Palmer, 1996). For the facilitator of the workshop it is essential to create an atmosphere, where there is a willingness to take risks and to prevent, that criticism causes team members to become afraid to put their ideas forward. Especially before and during the brainstorming session all kinds of negative feedback should be prevented.

\section{Think in functionality}

Value Analysis is based on analysis of the functions of each component of the project. This function analysis is made using the Function Analysis System Technique (FAST), a method conceived by Lawrence Miles in 1945 (Miles 1961).

By attributing the costs to the functions defined with Function Analysis System Technique (FAST), the 


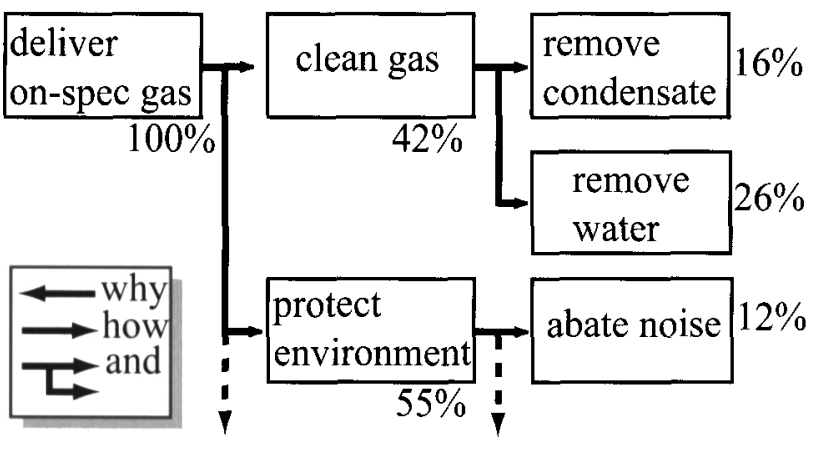

Fig. 3. A typical part of a Function Cost Diagram.

Value Analysis workshop can focus on the high cost elements. For each high cost element a brainstorm session is held to generate ideas how to deliver the functionality in a totally different way or to incrementally improve the current approach.

The Function Analysis System Technique (FAST) is a powerful method to move away from an existing design with existing design solutions and return to the basic functions and requirements of the project. During a Value Analysis, the team is totally focused on functions and basic requirements of an installation. This mode of thinking allows considering fundamentally different alternatives to fulfill a requirement, rather than coming up with only different design solutions.

\section{High focus}

Continuous focus is obtained by performing a Value Analysis workshop. Focus on functions rather than on design solutions, focus on high value items rather than on saving pennies, focus on opportunities rather than on barriers.

During the workshop the focus will shift from understanding the required functionality, to brainstorming on alternative engineering solutions and extensive evaluation of these alternatives. For participants, this means that the workshop never has a "dull" moment. On the other hand this implies a very demanding job for the facilitator of the Value Analysis workshop. The facilitator has to be able to guide the team through all stages of the workshop, without "losing" team members and without "losing" the open mind. This requires profound skills in group dynamics as well as an overview of the Value Analysis process.

\section{Extensive screening of ideas}

During the brainstorm session a massive amount of ideas will be generated. It is impossible and clearly uneconomic to study all those ideas in detail. Therefore, it is essential to quickly screen the ideas generated and only select the most promising for further evaluation.

This screening process is essential to the success of a Value Analysis. To select only the most valuable ideas a number of evaluation methods is typically used (Kaufman et al, 1994).

The methods used to screen the ideas range from fast methods used for filtering large numbers of ideas, to time-consuming group discussion of a small number of ideas. In both approaches each idea being evaluat-

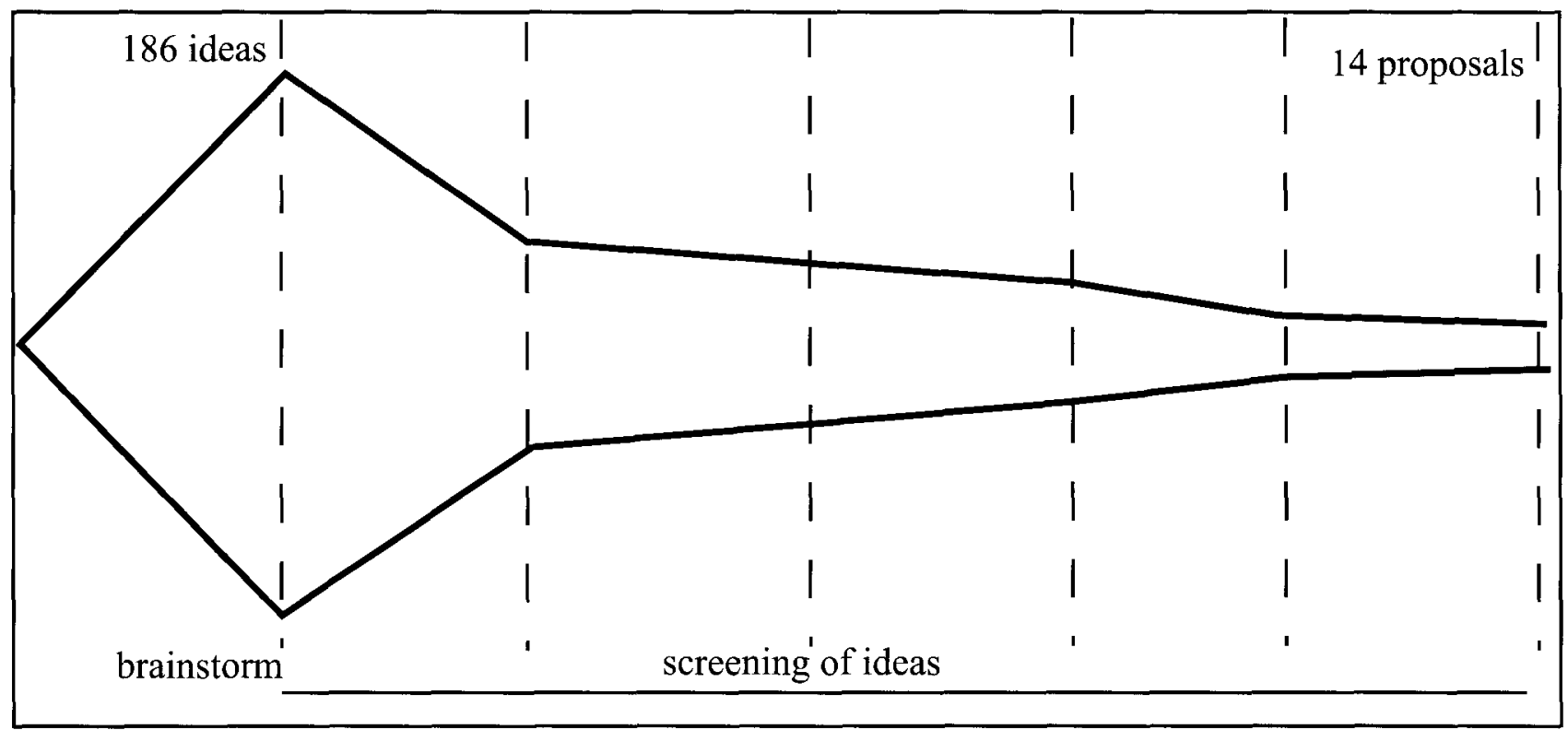

Fig. 4. Diverge quickly and converge carefully. 
Table 1. Typical results of Value Analysis workshops over the last two years.

Project

Engineering, Procurement and Construction (EPC) of

a major extension of an underground gas storage facility.

Proposal for an EPC contract to introduce lift-gas into an existing oil field to sustain production.

Engineering, Procurement, Construction and Maintenance of existing gas fields including the introduction of depletion compression.
Focus and result

Together with the client focus was on reduction of $\mathrm{TCOO}$ and project execution time. Both were reduced by $30 \%$.

The proposal team focused on reducing the Total Installed Cost (TIC) and increasing the Net Present Value (NPV) of the investment to prepare an alternative proposal to the Invitation to Bid. TIC was reduced by $15 \%$.

Together with the client focus was on TCoO of depletion compression and included the selection of various options to install compression-capacity. TCoO was reduced by $20 \%$. ed is worked into a proposal. Ideas that fail to raise sufficient support from the workshop team during the screening step are dropped.

To demonstrate how the evaluation process works, some typical methods, that can be used (Kaufman et al, 1994), are described below:

\section{Championing ideas}

In this fast screening phase each team member speaks in favour of those ideas he/she wants to champion. Only those ideas that are championed by at least one person, are retained for further evaluation.

\section{Gut feel index}

The gut-feel index is based on the assumption, that the gut feel of a group of experts (as present at the workshop) provides an objective assessment. Each team member has a deck of scorecards numbered from 1 to 10. After discussion of an idea by the idea champion the team scores it and the team average is recorded. Afterwards the team decides on a cut-off point above which the ideas will remain in the screening process.

\section{Proposal preparation}

For the remaining ideas team members are asked to volunteer for the writing of a short proposal (approx. $1 \mathrm{~A} 4$ ) on the idea, its fundamental assumptions and its opportunities. The ideas for which no one is willing to draft a proposal are eliminated from the screening process.

\section{Preparing a proposal menu}

In the final stage, those proposals influencing the same aspects are brought together and discussed in a small group. A menu is prepared of the most promising proposals and the potential benefits are quantified.

\section{Typical results of a Value Analysis}

The results of a Value Analysis vary as much as their objectives. Table 1 shows some typical results.

Key outcomes are, that client involvement is essential to a successful Value Analysis process and that cost saving opportunities can be found in virtually all Exploration and Production (EP) projects.

A significant additional benefit of a Value Analysis Workshop is the mutual trust and understanding created. This mutual trust and understanding between the project stakeholders is an excellent basis for starting a new project or enhancing existing projects.

\section{Conclusions}

The existing method of Value Analysis can easily be applied to Exploration and Production (EP) projects.

By applying the Value Analysis to Exploration and Production (EP) projects, cost savings can be achieved in the order of 10 to $30 \%$. Client involvement is a key success factor in capturing these cost saving opportunities.

A well-facilitated Value Analysis also leads to a mutual trust and understanding between the parties involved

\section{References}

Miles, L.D., 1961. Techniques of Value Analysis and EngineeringMcGraw-Hill Book Company New York.

Kaufman J.J. et al., 1994. Evaluating brainstorming ideas: "The making or breaking of the VE Workshop" . Annual Proceedings Society of American Value Engineers

Palmer, A., 1996. A comparative analysis of value management systems in the UK, USA and Japan, CIB Beijing international conference. 